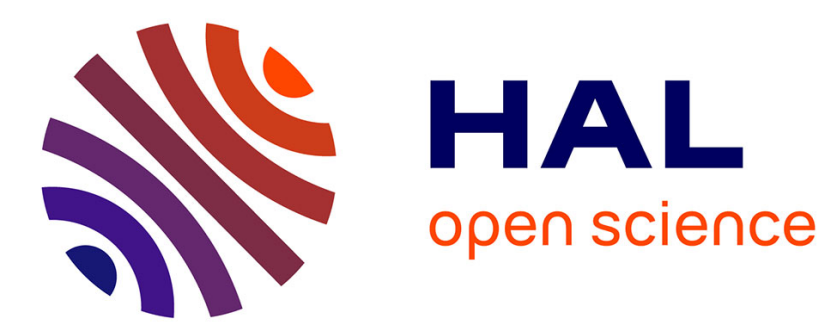

\title{
Prediction of Cleavage Probability Using Higher Order Terms of the Crack Tip Field
}

\author{
A. Brückner-Foit, G. Nikishkov, D. Munz
}

\section{To cite this version:}

A. Brückner-Foit, G. Nikishkov, D. Munz. Prediction of Cleavage Probability Using Higher Order Terms of the Crack Tip Field. Journal de Physique IV Proceedings, 1996, 06 (C6), pp.C6-307-C6-314. 10.1051/jp4:1996630 . jpa-00254458

\section{HAL Id: jpa-00254458 https://hal.science/jpa-00254458}

Submitted on 1 Jan 1996

HAL is a multi-disciplinary open access archive for the deposit and dissemination of scientific research documents, whether they are published or not. The documents may come from teaching and research institutions in France or abroad, or from public or private research centers.
L'archive ouverte pluridisciplinaire HAL, est destinée au dépôt et à la diffusion de documents scientifiques de niveau recherche, publiés ou non, émanant des établissements d'enseignement et de recherche français ou étrangers, des laboratoires publics ou privés. 


\title{
Prediction of Cleavage Probability Using Higher Order Terms of the Crack Tip Field
}

\author{
A. Brückner-Foit*, G.P. Nikishkov** and D. Munz,** \\ * IZSM, Karlsruhe University, P.O. Box 3640, 76021 Karlsruhe, Germany \\ ** IMF II, Forschungszentrum Karlsruhe, P.O. Box 3640, 76021 Karlsruhe, Germany
}

\begin{abstract}
The dependence of the Weibull stress is investigated on the parameters of the elasticplastic crack tip field. The general form of the Weibull stress is given for a three-parameter approximation of the elasto-plastic crack tip field. This is the basis to define a constraint correction of the critical value of the $J$-integral for cleavage fracture
\end{abstract}

\section{INTRODUCTION}

Good agreement between theory and experiment is obtained, if the cleavage fracture probability in the ductile brittle transition region of steels is evaluated using the local approach [1]. However, a threedimensional elasto-plastic finite element analysis has to be performed for cracked bodies in order to obtain the Weibull stress. Small variations of the stress field in the vicinity of the crack tip influence the value of the Weibull stress due to the high value of the Weibull exponent $m$.

At the beginning of the ductile-brittle-transion region, the crack tip field can be analytically described in terms of the HRR-field [2,3], if ductile damage has not occurred yet. It is well known [4] that the Weibull stress is proportional to $J^{2 / m}$, if the stress field ahead of the crack tip can be approximated by the HRR-field.

Higher order terms of the crack tip field play an important role for low constraint specimens [57]. It can be shown that a three-term approximation with two independent amplitudes is sufficient for commonly used specimens containing through-thickness cracks [8]. Hence the corresponding values of the Weibull stress depend on two parameters, the J-integral and a constraint parameter characterizing the amplitude of the higher order terms.

The objective of this paper is to study the dependence of the Weibull stress on the constraint parameter for typical fracture mechanics specimens. The three term asymptotic expansion of the elastoplastic crack tip field is summarised in the section 2 . Section 3 contains the evaluation procedure. Examples are given in the fourth section.

\section{THREE-TERM ASYMPTOTIC EXPANSION OF ELASTO-PLASTIC CRACK TIP FIELDS}

For a power law hardening material

$$
\frac{\varepsilon}{\varepsilon_{0}}=\frac{\sigma}{\sigma_{0}}+\alpha\left(\frac{\sigma}{\sigma_{0}}\right)^{n},
$$


the stress field in the neighborhood of a mode I crack tip under plane strain conditions can be described by the three-term asymptotic expansion $[5,6]$ :

$$
\frac{\sigma_{i j}}{\sigma_{0}}=A_{0} \bar{r}^{s} \tilde{\sigma}_{i j}^{(0)}(\theta)-A \bar{r}^{t} \tilde{\sigma}_{i j}^{(1)}(\theta)+\frac{A^{2}}{A_{0}} \bar{r}^{2 t-s} \tilde{\sigma}_{i j}^{(2)}(\theta) .
$$

In eqs. (1) and (2) $\sigma_{0}$ is the yield stress; $\alpha$ is the hardening coefficient; $n$ is the hardening exponent $(n>1)$; $\varepsilon_{0}=\sigma_{0} / E ; E$ is Young's modulus; $\sigma_{i j}$ are the stress components $\sigma_{r}, \sigma_{\theta}$, and $\sigma_{r \theta}$ in the polar crack tip coordinate system $r, \theta ; \tilde{\sigma}_{i j}^{(k)}$ are the dimensionless angular stress functions which depend on $n$ and are obtained from the solution of the linked asymptotic problems of zero, first and second orders; $s$ is a theoretically known eigenvalue for the problem of zero order, $s=-1 /(n+1)[2,3]$; values of an eigenvalue $t$ have been determined numerically in $[5,9] ; \bar{r}$ is a dimensionless radius:

$$
\bar{r}=\frac{r}{J / \sigma_{0}} .
$$

where $J$ is the $J$-integral. We assume that the angular stress functions $\tilde{\sigma}_{i j}^{(0)}$ and $\tilde{\sigma}_{i j}^{(1)}$ are normalized so that the maximum Mises equivalent stress is bounded by:

$$
\tilde{\sigma}_{e \max }^{(k)}=\left(\frac{3}{2} \widetilde{s}_{i j}^{(k)} \widetilde{s}_{i j}^{(k)}\right)_{\max }^{1 / 2}=1, \quad k=0,1 .
$$

where $\tilde{s}_{i j}^{(k)}$ are the deviatoric stress components and 'max' means the maximum for all angles. The coefficient $A_{0}$ is equal to:

$$
A_{0}=\left(\alpha \varepsilon_{0} I_{n}\right)^{-1 /(n+1)} \text {. }
$$

The scaling integral $I_{n}$ was introduced by Hutchinson in [2]. The coefficient $A$ is an amplitude parameter for the first and second order terms in the three-term asymptotic expansion of the crack-tip stress field. The value of $A$ can be determined by fitting expression (2) using the finite element stress data in the region which is significant for the fracture process [8].

\section{WEAKEST LINK MODEL FOR THE GEOMETRY DEPENDENCE OF $\boldsymbol{J}_{\boldsymbol{c}}$}

Within the framework of the local approach $[1,4]$ the cleavage fracture probability $P_{f}$ is given by

$$
P_{f}=1-\exp \left[-\left(\frac{\sigma_{W}}{\sigma_{u}}\right)^{m}\right]
$$

with the Weibull stress $\sigma_{W}$

$$
\sigma_{W}=\left(\frac{1}{V_{a}} \int_{V_{p t}} \sigma_{1}^{m} d V\right)^{\frac{1}{m}}
$$


where $V_{p t}$ is the volume of the plastic zone; $V_{0}$ is an arbitrary unit volume; $\sigma_{1}$ is the maximum principal stress at a given point; $m$ and $\sigma_{u}$ are the Weibull shape and scale parameters, respectively.

If the first term of the stress field, eq.(2), yields a good approximation of the crack tip field, it can be shown by a straightforward calculation [4] that the Weibull stress for a specimen containing a crack can be re-written as:

$$
\sigma_{W}=\left(\frac{J_{C}{ }^{2}}{\sigma_{0}{ }^{2}} \cdot \frac{B}{V_{0}} \int_{U_{p l}} \sigma_{1}^{m} d U\right)^{\frac{1}{m}}
$$

where $B$ is the specimen thickness, $J_{C}$ is the value of the $J$-integral at the onset of cleavage fracture and the integral does not depend on the load level. $U_{p l}$ is the volume of the plastic zone given in terms of the normalized radius $\bar{r}$, eq. (3), of a specimen of unit thickness. Eq.(8) is only applicable to two-dimensional cracks with a constant $J$-value along the crack front.

Higher order terms of the stress field, eq.(2), are needed in those cases in which there is a significant loss of constraint. Then the transformation leading to eq.(8) can still be performed, but the integral depends on the amplitude $A$ of the higher order terms of the crack tip field (see eq.(2)). Hence the Weibull stress is of the form:

$$
\frac{\sigma_{W}}{\sigma_{0}}=\left(\frac{J_{C}{ }^{2}}{\sigma_{0}{ }^{2}} \cdot \frac{B}{V_{0}} \cdot G(A, M)\right)^{\frac{1}{m}}
$$

where $M$ stands for the material parameters and $\sigma_{0}$ is a normalization factor, e.g. the flow stress. The dimensionless function

$$
G(A, M)=\int_{U_{p^{l}}}\left(\frac{\sigma_{W}}{\sigma_{0}}\right)^{m} d U
$$

depends only on the value of $A$ and hence on the load level and not explicitly on the crack size or the specimen geometry.

The value of the amplitude $A$ under small scale yielding conditions is completely determined by the elastic crack tip field and the corresponding values of $K$ and $T$. Hence the small scale yielding value of $A, A_{S S Y}$, is identical with the value of $A$ obtained by the modified boundary layer solution for small scale yielding, i.e. the solution of an elastic-plastic boundary value problem with boundary conditions corresponding to the elastic stress or displacement fields in the near crack tip region given in terms of suitably selected values of the stress intensity factor $K$ and the amplitude $T$ of the second term of the elastic crack tip field. A special case is the elastic crack tip field with $T=0$ for which the relation $\sigma_{W} \propto K^{4 / m}[4]$ is valid.

The following relation holds at a given value of the Weibull stress corresponding to a specific value of the failure probability:

$$
\frac{J_{C}^{2}}{J_{S S Y}^{2}}=\frac{G\left(A_{S S X}, M\right)}{G(A, M)},
$$

Eq.(11) can be used to transform the measured value of the J-integral, $J_{C}$, into a equivalent small scale yielding value $J_{S S T}$. This implies that the failure probability, eq.(6), can be written in terms of a Weibull distribution for the transformed values $J_{S S Y}$ with a shape parameter equal to 2 


\section{PREDICTION OF $J_{d} J_{I c}$ FOR TYPICAL SPECIMENS}

Four typical specimens are considered in this paper:

(a) edge cracked plate (ECP);

(b) center cracked plate (CCP);

(c) three-point bend specimen (3PB);

(d) compact tension specimen (CT).

Limit loads for rigid-plastic bodies are used to normalize the applied loads:

ECP:

$$
\sigma_{L}=1.455 \sigma_{0} \frac{a}{W}\left(-1+\sqrt{1+\left(\frac{W-a}{a}\right)^{2}}\right),
$$

CCP:

$$
\sigma_{L}=\frac{2}{\sqrt{3}} \sigma_{0}(W-a)
$$

3PB:

$$
P_{L}=1.455 \sigma_{0} \frac{W^{2}}{2 H}\left(\frac{W-a}{W}\right)^{2},
$$

CT:

$$
P_{L}=1.455 \sigma_{0} W\left(-1-\frac{a}{W}+\sqrt{2+2\left(\frac{a}{W}\right)^{2}}\right) .
$$

The following material data are specified:

$\begin{array}{ll}\text { Elasticity modulus, } E & E / \sigma_{0}=500 ; \\ \text { Poisson's ratio, } & v=0.3 ; \\ \text { Hardening coefficient, } & \alpha=0.5 ; \\ \text { Hardening exponent, } & n=10 ; \\ \text { Yield stress, } & \sigma_{0}=1 ; \\ \text { Weibull shape parameter, } & m=20\end{array}$

All stresses are given in terms of multiples of $\sigma_{0}$.

The Weibull stresses are calculated in two different ways. First an elasto-plastic finite element analysis is performed with the finite element code ABAQUS [10] using deformation plasticity theory with small strain formulation. A typical finite element mesh (376 8-noded isoparametric elements of reduced integration elements, 1209 nodes, the smallest element $r_{1} / W=10^{-4}$ ) for specimen configurations (a), (b) and (c) is shown in Fig. 1. The stresses reach very high values at the crack tip, as crack tip blunting is not taken into account. From large strain calculations it is known that the stresses approach a maximum approximately at a radial position $\bar{r}_{0}=1$. In this paper the maximum stress $\sigma$ is set to be constant along a radial ray $\bar{r}<1$ and equal to the value of maximum stress at the point $\bar{r}=1$ and the corresponding angle $\theta$.

The numerical integration for a polar mesh of 8-node finite elements is performed in the following way. For the current value of the $J$-integral the original finite element mesh is transformed into a mesh with an outer boundary of the first element ring at $\vec{r}=1$ as shown in Fig. 2. The maximum stress $\sigma$ is constant along the radial rays of finite elements composing the first ring (element $A$ in Fig.2). Stresses in the element $B$ of the transformed mesh are obtained by bilinear interpolation of stresses in the element $C$ of the original finite element mesh. Then Gaussian integration is carried out for all integration points situated inside the plastic zone.

The second evalution method for $G(A)$ is based on the three term expansion of the stress field, eq. (2). The integration is performed using the same mesh as for the finite element analysis. However, the number of evaluation points within a given element can now be increased in order to improve the 

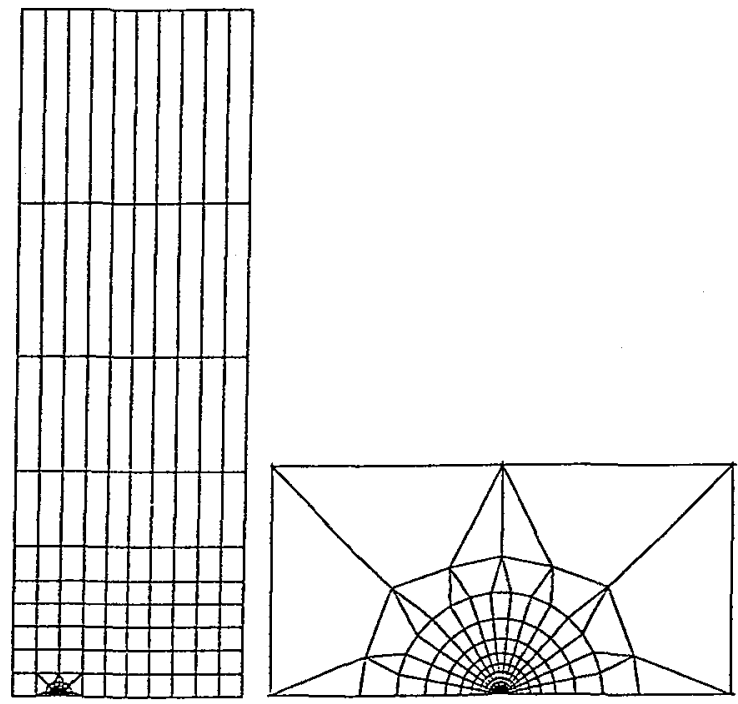

Figure 1: Finite element mesh in the vicinity of the crack tip

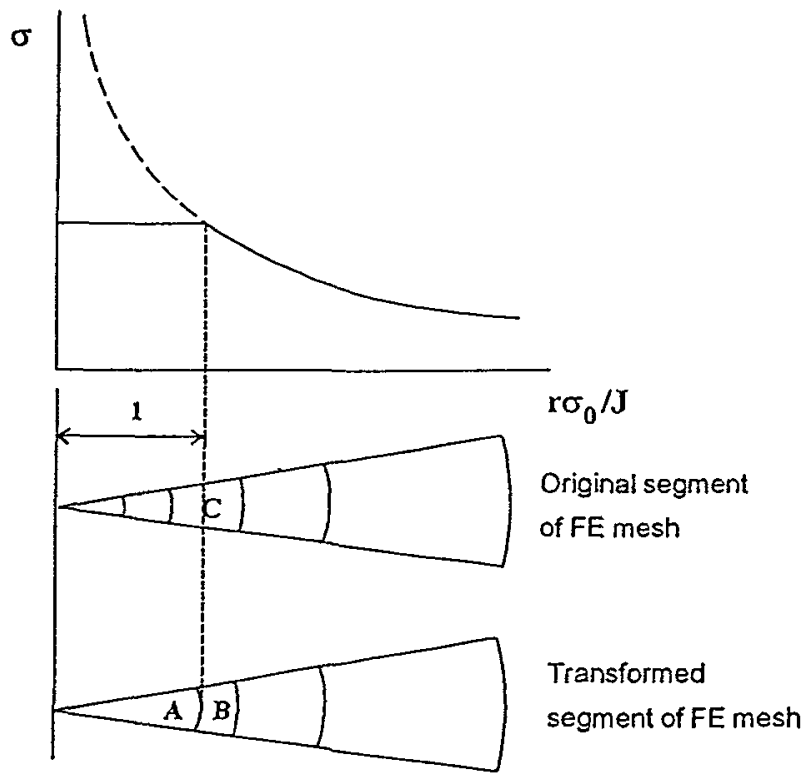

Figure 2: Integration domains for the evaluation of the Weibull stress

numerical accuracy of the integration procedure. The cut-off procedure for the singular stresses at the crack tip is identical with the one used for the finite element results.

The function $G$ for an edge cracked plate, a center cracked plate, a three-point bend specimen and a compact tension specimen with different cracks as a function of the normalised stress $\sigma / \sigma_{L}$ or the normalised load $P / P_{L}$ are presented in Fig. 3-6. Values obtained by integration of FEM stresses are 
shown by points. Solid lines are the corresponding values obtained by integration of the three-term stress approximation. All values are normalised with the value of the function $G$ which was obtained by solving the modified boundary value problem for $T=0$ and very small values of $K$. It can be concluded that the Weibull stresses obtained by the three-term stress approximation agree with the FEM data fairly well, except some points for high loads, and some scatter in the FEM data which are clearly related to problems of the mesh.

In Fig. 7, the normalised $G$-function is plotted as a function of the amplitude $A$. All the FEMvalues are plotted as symbols. A closed form expression for the function $G$ can be obtained by a curve-fit to the points shown in Fig.7. Good agreement was found for the following function (solid line in Fig.7):

$$
G(A, M)=\exp \left(a_{0}(M)+a_{1}(M) \cdot A+a_{2}(M) \cdot A^{2}\right)
$$

with the material dependent coefficients $a_{i}$. The following coefficients were obtained for the material data specified above: $a_{0}=0.274 ; a_{1}=2.22 ; a_{2}=-18.0$.

\section{CONCLUSION}

The Weibull stress determining the failure probability for cleavage fracture can be expressed in terms of the J-integral and the amplitude $\mathrm{A}$ of the higher order terms, if the elasto-plastic crack tip field is approximated by a three term expansion. A comparatively simple analytical expression is obtained by a curve-fit to FE-results obtained for fracture mechanics specimens containing through-thickness cracks. On the basis of these results a contstraint corrected value of the J-integral can be defined, if the values of $\mathrm{J}$ and $\mathrm{A}$ at fracture are known, and if the corresponding small scale yielding values are available

\section{References}

[1] Beremin, F.M., Metallurgical Transactions A, 14A (1983) 2277-2287.

[2] Hutchinson, J.W., J. Mech. Phys. Solids, 16 (1968) 13-31.

[3] Rice, J.R. and Rosengren, G.F., J. Mech. Phys. Solids, 16 (1968) 1-12

[4] Mudry, F., Nuclear Engineering and Design, 105 (1987) 65-76.

[5] Yang, S., Chao, Y.J. and Sutton, M.A., Eng. Fract. Mech., 45 (1993) 1-20.

[6] Xia, L., Wang, T.C. and Shih, C.F., J. Mech. Phys. Solids, 41 (1993), 665-687.

[7] O'Dowd, N.P. and Shih, C.F., J. Mech. Phys. Solids, 39 (1991) 989-1015.

[8] Nikishkov, G.P., Brückner-Foit, A. and Munz, D., Eng. Fract. Mech. 52 (1995)685-702.

[9] Nikishkov, G.P., Eng. Fract. Mech. 50 (1995) 65-83.

[10] ABAQUS Version 4.8, Hibbit, Karlsson and Sorensen, Inc., Providence, RI (1990). 


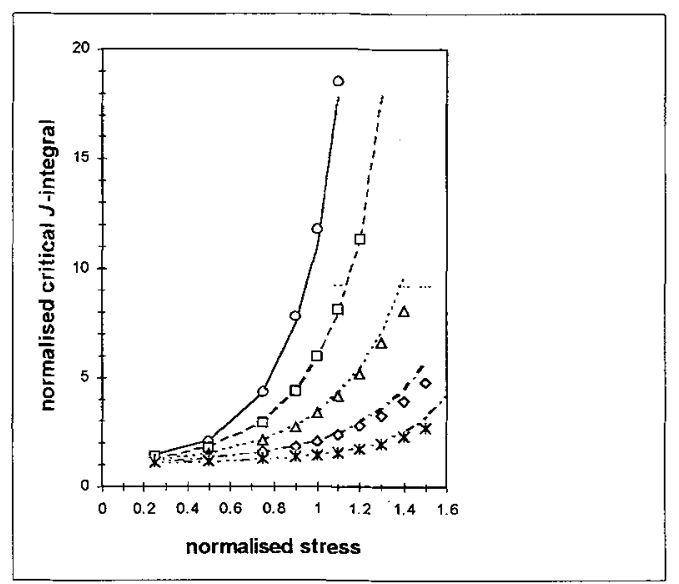

Figure 3: Critical value of the normalised $J$ integral at cleavage fracture; edge cracked plate;
$\mathrm{O}-\mathrm{a} / \mathrm{w}=0.1, \square--\mathrm{a} / \mathrm{w}=0.2$,
$\Delta-\cdots \mathrm{a} / \mathrm{w}=0.3,0 \ldots \mathrm{a} / \mathrm{w}=0.4$,
* - - a $\mathrm{a} w=0.5$.

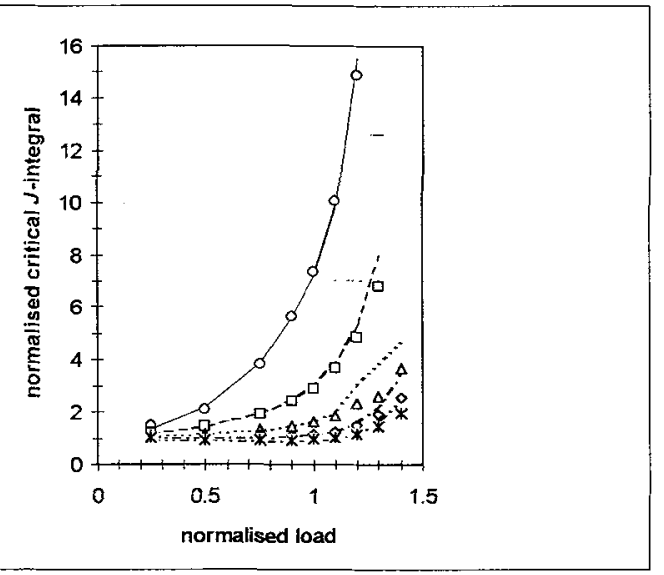

Figure 5: Critical value of the normalised $J$ integral at cleavage fracture; 3-point bending specimen;

$\mathrm{O}-\mathrm{a} / \mathrm{w}=0.1, \square-\cdots \mathrm{a} / \mathrm{w}=0.2$,

$\Delta-\mathrm{a} / \mathrm{w}=0.3,0 \ldots-\mathrm{a} / \mathrm{w}=0.4$,

$*-\cdots-\mathrm{a} / \mathrm{w}=0.5$.

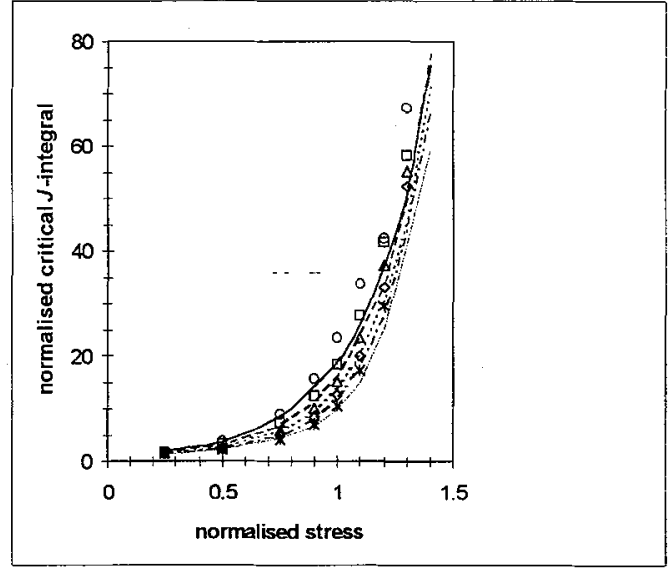

Figure 4: Critical value of the normalised $J$ integral at cleavage fracture; centre cracked plate; $\mathrm{O}-\mathrm{a} / \mathrm{w}=0.1, \square--\mathrm{a} / \mathrm{w}=0.2$,
$\Delta-\cdots \mathrm{a} / \mathrm{w}=0.3,0 \ldots-\mathrm{a} / \mathrm{w}=0.4$,
* - - $\mathrm{a} / \mathrm{w}=0.5$.

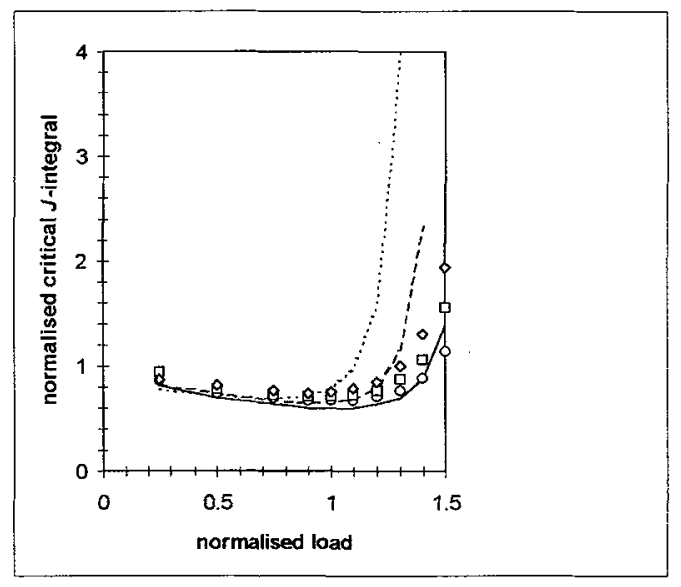

Figure 6: Critical value of the normalised $J$ integral at cleavage fracture; CT-specimen;

$\mathrm{O}-\mathrm{a} / \mathrm{w}=0.5, \square--\mathrm{a} / \mathrm{w}=0.6$,

$0 \ldots a / w=0.7$. 


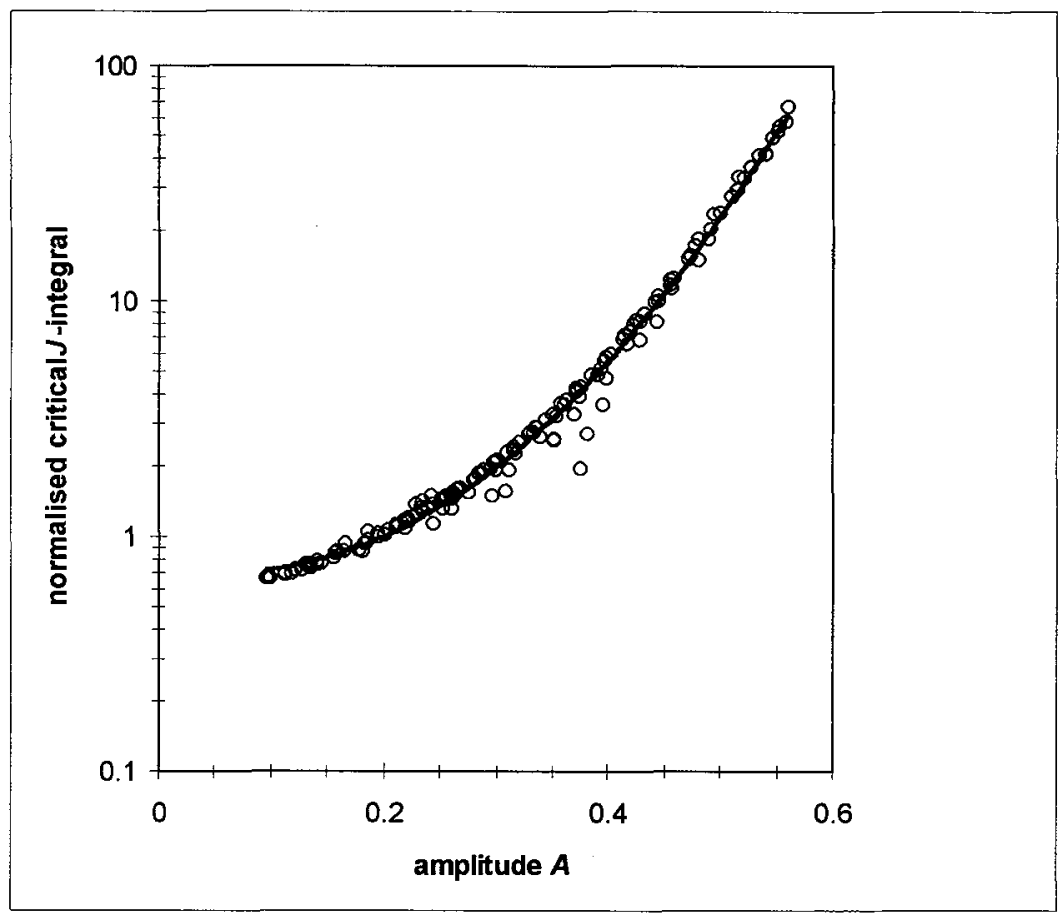

Figure 7: Critical of the normalised J-integral at cleavage fracture; $\mathrm{O}$ FE results; — curve fit using eq. (13). 